\title{
Controversies in medical publishing; messages from New Delhi
}

One of us (RY) has just returned from New Delhi after attending the 1st Conference of The World Association of Medical Editors. It is always refreshing attending a conference in which one's own clinical work is not the principle focus. There is the opportunity to mix with those from other disciplines and from the publishing industry. The meeting was well attended, with over 200 delegates, mostly from South Asia. The most striking observation was of the gross dichotomy in the medical publishing world based entirely on wealth. Wealthy countries have profitable publishing industries supporting high levels of production and attracting much quality content from around the world. In contrast, low- and middle-income countries have a poorly resourced publishing infrastructure. This lack of resources, combined with the pressure to publish in some countries, has led to article numbers being used as a 'currency' in appointment and promotion to academic positions. Although to some extent this is a worldwide trend, the situation is particularly acute in India where a 'perfect storm' has in large parts driven the development of so-called 'predatory journals'. We have mentioned this phenomenon in a previous editorial, ${ }^{1}$ but basically it involves the fabrication of journal titles in order to attract articles that are 'published' in return for money. The peer review is absent or fabricated in these 'journals', as is indexing and often traceability. Unfortunately, these articles often turn up when subjects are investigated in the major search engines such as Google.

Another feature of medical publishing, mirroring what is happening outside of medicine, is the desire of modern culture to access information in small bites, immediately. The use of social media is a large feature of this, and is being embraced by many in the publishing world. The advantage of this development is the rapid dissemination of information to the public as well as medical professionals, which can only be a good thing, as long as the information remains evidence-based and is not misleading. New web platforms such Cureus ${ }^{2}$ and Health News Review ${ }^{3}$ are part of this 'rapid learning community'. Other resources new to authors include the Equator Network, ${ }^{4}$ which neatly summarises reporting guidelines for clinical trials.
One almost universal feeling amongst the medical editors present in New Delhi was the despair at 'impact factor' being used as a measure of journal quality. Editors felt that this index very rarely reflected the true 'quality' of a journal and often led to journals whose content was of little interest to active clinicians, as opposed to those in pure research. Editors agreed that chasing impact factor often led to manipulative practices that detracted from the true quality of a journal's content.

This issue of The Journal of Laryngology \& Otology contains a number of articles featuring topics of great importance to active ENT clinicians. These include an analysis of the cost effectiveness of acoustic neuroma screening, ${ }^{5}$ a comparison of different tonsillectomy techniques, ${ }^{6}$ and a review of biomarkers predicting chemotherapy response in advanced head and neck cancer. ${ }^{7}$ Also of interest to those of both sexes with greying hair, is that this feature, when it presents prematurely, appears to be associated with hearing loss at high frequencies. ${ }^{8}$

\section{ROBIN YOUNGS EDWARD FISHER Senior Editors}

References

1 Youngs R, Fisher E. Predators and moustaches. J Laryngol Otol 2015;129:111

2 Cureus. In: www.cureus.com [4 October 2015]

3 Health News Review. In: www.healthnewsreview.org [4 October 2015]

4 Equator Network. Enhancing the QUAlity and Transparency Of health Research. In: www.equator-network.org [4 October 2015]

5 Pan P, Huang J, Morioka C, Hathout G, El-Saden SM. Cost analysis of vestibular schwannoma screening with contrast-enhanced magnetic resonance imaging in patients with asymmetrical hearing loss. J Laryngol Otol 2015;129: DOI 10.1017/ S0022215115002431

6 Elbadawey MR, Hegazy HM, Eltahan AE, Powell J. A randomised controlled trial of coblation, diode laser and cold dissection in paediatric tonsillectomy. J Laryngol Otol 2015;129:1058-63

7 Cosway B, Paleri V, Wilson J. Biomarkers predicting chemotherapy response in head and neck squamous cell carcinoma: a review. J Laryngol Otol 2015;129:1046-52

8 Ozbay I, Kahraman C, Kucur C, Namdar ND, Oghan F. Is there a relationship between premature hair greying and hearing impairment? J Laryngol Otol 2015;129:1097-1100 